PART II

Chapter 15

\title{
Presentation of Results, Tables and Basic Indicators
}




\section{Introduction}

Health expenditure is the object of measurement in health accounts. A country's health accounts (HA) provide the measurements for a given time period and present these in a set of tables in which various aspects of the nation's health expenditure are arrayed. The tables themselves are simply a means to display the financial flows related to a country's consumption of health care goods and services. The data contained are intended for use by analysts and national policy makers to assist in assessing and evaluating a country's health system. Reporting the data and estimates in a comparative way allows for evaluations between countries and is thus useful for international comparisons.

While it is important to understand that tables provide a systematic way to report health accounts data, policy makers will often request that information be presented in a form that is concise and immediately meaningful in terms of its relation to policy questions. Key results will often need to be extracted from the tables, as well as linked to non-expenditure data, such as on outputs and outcomes, in order to explicitly inform decision makers about specific emerging issues or about the progress of policies already implemented and their observed impacts.

Three main ways that a country's health accounts for each time period are disseminated and systematically archived are, first, through the regular dissemination of selected indicators, and, second, through periodic reporting via national, regional and international databases. The third method would be a report summarising the health accounts prepared each time a round of estimates is produced.

- Health accounting indicators represent the most frequent way that health accounts data are disseminated. They usually cover a Minimum Data Set for which (current) expenditure on health as a total is presented, e.g. as a share of GDP, and in per capita values, among others.

- HA results of countries are also reported and tracked in national, regional and international databases. These databases generally maintain historical data for countries, but can sometimes provide less detail compared to country HA reports.

- A summary report should present HA results in a systematic manner. The contents of the report should be useful to different audiences and for various purposes, but, more importantly, relevant to national policy issues. It should also contain any necessary information on data sources and methods.

This chapter contains a discussion of the suggested content of an HA report. It also discusses the issue of harmonising country data across databases. One objective of this chapter is thus to bring about some degree of comparability in future HA reports across countries to facilitate, not only national, but also international use of country data. Another objective of the chapter is to emphasise the need for HA records to provide careful documentation of sources and methodological information so that observed differences, say, for one country over time and between countries, can be understood and put into proper context. 


\section{The health accounts report}

The basic content of an HA report should ideally include the following: a number of tables and indicators that will inform sound national policy and good governance; country background information to provide the context to better understand the HA findings, including reference information for computing indicators; and brief documentation of the HA data sources and any methodological information that is important to properly interpret the HA results. Among the basic set of tables in an HA report the tables on HCxHP, HCxHF, HFxHP as well as HFxFS could be considered. Each of these topics is discussed further. Additionally, HA time series, the use of HA combined with other health-related data and quality checks of HA results are also discussed.

\section{Health accounts tables}

The rows and columns of the HA tables incorporate the various classifications presented in this Manual. The classifications or dimensions of health expenditure include the following:

- Functions (HC): the types of goods and services provided and activities performed within the health accounts boundary;

- Providers (HP): entities that receive money in exchange for or in anticipation of producing the activities inside the health accounts boundary:

- Financing schemes (HF): components of a country's health financial system that channel revenues received and use those funds to pay for, or purchase, the activities inside the HA boundary;

- Financing agents (FA): institutional units that manage health financing schemes;

- Financing sources (FS): the revenues of the health financing schemes received or collected through specific contribution mechanisms;

- Factors of provision (FP): the types of inputs used in producing the goods and services or activities conducted inside the HA boundary;

- Beneficiary characteristics of those who receive the health care goods and services or benefit from those activities (beneficiaries can be categorised in many different ways, including their age and gender, their socio-economic status, their health status and their location);

- Capital formation (HK): the types of the assets that health providers have acquired during the accounting period and that are used repeatedly or continuously for more than one year in the production of health services;

- Trade in health: imports of health care goods and services provided to residents by nonresident providers, and exports of health care goods and services provided to non-residents by resident providers;

- Products: the various goods and services provided by the providers, including the nonhealth care goods and services produced and consumed.

The classifications can be applied to health expenditures individually to produce expenditure tabulations by a single dimension. Although this type of data presentation can be very useful as a starting point, and it can be used for specific issues of high relevance within the health system, there is additional information to be gained from crossclassifying expenditures using two or more classifications. 
HA tables basically involve cross-classification. Although many combinations of tables can be created using all the dimensions listed above, only a selection of tables that are typical of tables that might be included in an HA report are presented. A number of these tables are of particular interest for international comparisons. For national purposes, the list of proposed tables can represent a "menu" from which health accountants can choose, while always bearing in mind that these tables are not the only ones of potential value. Each country's policy makers have their own information needs that must be addressed using health accounts data. Producing any tables at all is certainly better than producing none. Producing more will often be preferable to producing fewer, although it may be better to concentrate on a few key tables when faced by resource constraints. The choice of which tables to produce should be linked to their potential usefulness as well as to the feasibility of their construction. ${ }^{1}$

SHA revolves around a tri-axial approach to estimation where it is expected that the value of health care goods and services estimated from the consumption side should coincide with the values estimated from the provision and the financing sides. Thus, the cross-classification of the three axes or dimensions defines a basic set of tables with credible HA estimates that countries might expect to produce and report. Experience in countries where health accounts have been created indicates that the application of the three classifications (functions, providers and financing schemes) is critical to obtaining a realistic estimate of total current health spending. The HA tables that cross-tabulate these dimensions are important tools for creating consistent aggregate totals and subtotals across HA tables.

Most of the HA tables described in this chapter are two-dimensional tables. Each table represents a specific type of health financial transaction or resource flow, where the flows have on one side the origins of the funds and on the other side the recipients or the uses of those funds. By convention, the columns of the HA tables show the "origins", and the rows the recipients or "uses" of the resource flows. The labels of HA tables refer first to the row classification (uses) and then the column classification (origin), e.g. the table showing the resource flow from financing schemes (HF) to providers (HP) is referred to as the HPxHF table. The sequence of transactions or resource flows through the health care system can be captured through a series of HA tables: from financing sources and types of revenues to financing schemes, from financing schemes to providers, and from providers to the health care goods and services consumed, and, finally, to how these are distributed among beneficiaries.

The tables that illustrate what may be included in the HA report are described below, together with generic depictions of the tables. The first three tables cross-classify expenditures according to the three main dimensions of the tri-axial approach of the SHA.

\section{Health expenditure by type of financing scheme and by function (HCxHF)}

The table showing health expenditure by type of financing scheme and type of function (see Table 15.2) describes the overall and specific allocation of resources to the major types of health care services by the financing schemes. This table highlights the resource paths that are key for informing health analysts. It addresses the question of "who funds what" and allows the identification of both these functions where resources are concentrated and their main funding paths. Experience shows this table to be important for validating estimates of the demand side of current health spending. 


\section{Health expenditure by type of provider and by function ( $\mathrm{HCxHP}$ )}

The table showing current health expenditure by type of provider and by function (see Table 15.3) shows how expenditures on different health functions are channelled through the various types of providers. That is, it tells the user "who provides what". This table provides a summary perspective of the health market in a country, i.e. what is the structure of its health care needs and who are the providers involved. This table has been shown to be valuable for validating the supply side of the CHE estimate.

\section{Health expenditure by financing scheme and by type of provider (HPxHF)}

This table shows the structure of current health expenditure according to the financing arrangements (financing schemes) for providing the financial means to the providers (see Table 15.4). It describes how funds are distributed across different types of providers and addresses the question, "who funds who". The table allows the user to identify those providers where resources are concentrated and their funding paths. Experience with health accounting has shown that the HPxHF table is an important tool for estimating total current health spending, and it should be an early focus in the initial work.

\section{Types of revenues by revenues of the financing scheme (HFxFS)}

This table shows the financing path to fund the various schemes (see Table 15.5). Actually, the institutional units collect the funds used to finance the schemes. The table addresses the question "where does the money come from" by showing the types of revenue of each financing scheme. The table also displays the relative importance of each type of revenue in the financing of each financing scheme and in total current spending overall.

\section{Health expenditure by financing agent and by financing scheme (HFxFA)}

The table shows each scheme and how much of its expenditure is managed by each agent (see Table 15.6). This table displays the institutional structure of health financing by indicating the relationship between the schemes and agents. The table addresses the question of "who manages which payment scheme". Financing agents are usually the starting point in the construction of the tables of financing schemes, as they are the origins of the data for this exercise.

\section{Factors of provision by type of provider (HPxFP), by type of function (HCxFP)} and by financing scheme (HFxFP)

The information on the mix of factors of provision is a key monitoring tool in determining overall system performance, and it provides a basis for the analysis of the efficiency of production and resource use. Factors of provision can be cross-classified against three other classifications: HP, HC and HF. The first table shows the allocation of factors by provider on different types of resources used to produce health care goods and services (see Table 15.7). The question addressed by this table is, "what are the various inputs used in the provision process and by which specific provider groups". The second option shows the allocation of different types of factors among the various types of health care goods and services (grouped by functions). The question addressed by this table is "what are the various inputs used for provision of specific goods and services". The third possible table shows how the different factors used in health care provision are financed. The question addressed by the HFxFP table is, "who pays for the various inputs used in the provision". 


\section{Expenditure by type of provider and capital goods (HKxHP)}

This table (see Table 11.2 in Chapter 11) shows the net value of the capital goods by type of asset acquired by the various providers. It shows "who is investing" to expand physical capacities to provide health care and the types of investments. It gives insight into the future capacity of the various providers.

\section{Expenditure by financing agent and by capital goods (HKxFA)}

This table provides an overview of how the acquisition of the capital goods is financed. The question addressed by the table is "who pays for investment". Investment is displayed by type of asset or durable goods. It gives an insight into the way the investments of health providers are funded and whether this financing structure can be sustained.

\section{Trade in health care: exports and imports (HC.XxHP and HC.MxHF)}

These kinds of tables (Tables 12.2 and 12.3 in Chapter 12) show the two components of trade: exports of health care goods and services by types of health function provided to non-residents by different resident providers; and imports of health care goods and services by type of health function provided to residents by non-resident providers, as well as how these functions are paid for. The basic data on imports are also shown in the HCxHP table - the entries in the column for Rest-of-the-world providers (HP.9) are the values of imports, but the values of exports are implicitly excluded from the domestic health providers columns (HP.1 to HP.8). Trade in health care has seen significant growth in many countries for several reasons, including, among others, technological advances, ease of movement of patients and medical professionals, the portability of insurance, and differentials in the prices of health care service across countries. While there is an increasing interest in measuring and reporting the extent of such trade because of its implications on regulation and investment in health in a country, nonetheless for many countries it remains a marginal phenomenon in the overall health accounts.

\section{Expenditures on health care by disease/condition}

These tables can show health expenditure by major GBD group (or ICD-10 chapter) cross-classified by health care function, provider and financing scheme. These are some of the more challenging tables to produce, as this requires reliable health conditions data or diagnostic data from providers and/or patients that can be linked to expenditure data. With the function dimension, the table can show the types of health care services used to treat different disease groups, and how each service is allocated (in financial terms) between the different disease groups. With the provider dimension, the table shows who provides the health activities that address each type of disease or condition and what share of their total revenues relates to each disease. With the financing scheme dimension, the table shows who pays for the health activities that address different health conditions and what share of each scheme's spending relates to each disease group. These questions are important as an input to how health financial resources may be allocated to various uses, and to provide information for policy formulation and for the design and implementation of health programmes. ${ }^{2}$

\section{Expenditure on health care by age and gender}

The table shows health expenditure by age and gender of the beneficiary, crossclassified by health care function, provider or financing scheme. Health care requirements 
vary with age, with the young, the elderly and women of childbearing age generally requiring more health care. The table provides information that can be used to assess the age/gender targeting of expenditures of specific financing schemes; for example, is the government scheme successful in increasing support for child health, elderly health and women's reproductive health programmes? The same holds for questions about the functions and providers classification: which health care services and providers are reaching specific age groups of the population?

\section{Expenditure on health care by income quintile}

The table shows health expenditure by income group of the beneficiary of expenditure, cross-classified by health care function, provider and financing scheme. The portion of the table cross-classified with functions and providers can help to assess access (in financing terms) to specific types of health care services and to providers according to beneficiaries' capacity to pay. The portion of the table cross-classified with financing schemes shows: how the composition of financing for health care varies with income class; what share of health spending is being borne by different income groups; and how well specific schemes, such as the government scheme and social health insurance, target vulnerable groups.

\section{Multi-dimensional tables}

Three dimensions can also be used in a single table. For example, revenues of schemes could be crossed with financing schemes, and then crossed further with providers or functions. The information from the table helps link the origin of the funds funnelled into the health system to their final uses. For example, in countries with high external funding or with a high level of government transfers, a three-dimensional table can help identify whether government revenues or foreign aid are addressing key needs (for example, prevention vs. curative; hospitals vs. district ambulatory services).

\section{Selected HA indicators}

In addition to the tables, a health accounts report should also summarise key results in the form of indicators. An indicator is defined as a measurable variable that is used as a representation of an associated phenomenon. Health accounts indicators are measurements in reduced form that represent the different aspects or attributes of a country's health expenditures and health financing system. If health accounts are to be viewed as a measuring tool, the indicators are the measurements or readings derived from this tool.

A modest selection of indicators, as listed below in Table 15.1, is provided as an example of what may be included in countries' health accounts reports. The indicators in the list are computed either using purely HA results or in combination with additional macro-economic and non-expenditure data. Indicators of the first type include absolute expenditure levels, percentage shares to total and ratios of one health accounts component to another. Indicators of the second type include share of GDP, per capita values and values converted using exchange rates or PPPs.

In general, indicators for policy analysis can be created from the most important cross-tabulations. Examples are the share of prevention in hospital services; the ratio of inpatient and outpatient spending financed by government; and the level of capital spending targeted in publicly owned hospitals. 
The levels of detail in these cross-tabulations may be specified differently in the regions of the world. The focus in the European Union relates to concerns among the Member States. ${ }^{3}$ Some regional communities, such as the Commonwealth of Independent States (CIS), the Caribbean Community (CARICOM) and the MERCOSUR ${ }^{4}$ have their own specific needs, which may make the reporting of certain HA tables a priority. As a result of this situation, some indicators that are feasible in one region may not be feasible in another one.

However, in all countries where HA have been established, health expenditure estimates classified according to only one key would generally be available, especially expenditures classified by function, provider and financing scheme. These data also provide information that address specific policy issues. Examples include the total amount of out-of-pocket health expenditures, the amount paid to hospitals, and the amount spent for prevention. Aggregates such as total spending on pharmaceuticals (adding inpatient use of pharmaceuticals to outpatient use) have also been of interest to policy makers. Another example is the amount spent on long-term care, summing both the health care part and the social part. Traditional medicine is also a topic of special policy interest in some parts of the world.

The indicators that a country decides to adopt do not have to be limited to the proposed list. Many more can be created, usually to meet national or even local needs. For example, the additional indicators that some countries have expressed an interest in include the following: total contributions of households to financing schemes through the different contribution mechanisms; expenditures of government schemes and compulsory financing schemes as a percentage of general government expenditures; expenditures on communicable diseases; expenditures supporting the Millennium Development Goals (MDGs); and health expenditures in specific geographic areas. The calculation of these additional indicators may require the use of reporting items of classifications (e.g. reporting item for functions for expenditures on communicable diseases and preventive health programmes). Other indicators may require the creation of new aggregates that need to be reported as memorandum items of the appropriate tables. For example, to calculate expenditures supporting MDGs, an aggregate consisting of expenditures for specific diseases (named in the MDG) needs to be constructed from either of the sets of tables showing disease breakdown, ICD-10 chapter or Global Burden of Disease category. Also, total contributions of households to financing schemes include the social health insurance contributions of employees and self-employed, voluntary pre-payment from households/ individuals and other revenues from households.

Table 15.1 shows examples of some of the more frequently requested values, but those not included and considered to be useful can also be calculated. See Box 15.1 below for one example on levels of care.

\section{HA time series}

The use of commonly-agreed classifications and boundaries as set out in the SHA Manual should result in data that can be better compared across countries, and nationally should provide more consistent data over time. For example, a standard definition of health care based on the functional boundary can avoid sudden changes in national aggregates due to a change in responsibilities of the various ministries and the resulting reorganisation of various programmes. This makes it possible both to monitor and follow 
Table 15.1. Selected examples of indicators used in health care analysis

\begin{tabular}{|c|c|c|c|c|c|c|c|c|c|}
\hline Axis & Indicator & $\begin{array}{l}\text { Min } \\
\text { NCU }\end{array}$ & $\begin{array}{l}\text { USD or } \\
\text { EUR }\end{array}$ & PPP & $\%$ GDP & $\begin{array}{c}\text { Per } \\
\text { capita } \\
\text { NCU }\end{array}$ & $\begin{array}{c}\text { Per } \\
\text { capita } \\
\text { USD or } \\
\text { EUR }\end{array}$ & $\begin{array}{l}\text { Per } \\
\text { capita } \\
\text { PPP }\end{array}$ & $\begin{array}{c}\text { Percentage of } \\
\mathrm{CHE}\end{array}$ \\
\hline \multirow[t]{2}{*}{ General } & Total current health expenditure & $x$ & $x$ & $x$ & $X$ & $x$ & $x$ & $x$ & \\
\hline & Total current health expenditure plus capital spending ${ }^{5}$ & $x$ & $x$ & $X$ & $X$ & $X$ & $X$ & $x$ & \\
\hline \multirow{7}{*}{$\begin{array}{l}\text { Health } \\
\text { functions }\end{array}$} & Preventive spending & & & & & & & & $x$ \\
\hline & Curative spending & & & & & & & & $X$ \\
\hline & Inpatient spending & & & & & & & & $X$ \\
\hline & Outpatient spending & & & & & & & & $X$ \\
\hline & Health expenditure on long-term care & $x$ & $x$ & $x$ & & & & & $x$ \\
\hline & Total LTC spending & $x$ & $x$ & $\mathrm{X}$ & $x$ & $\mathrm{x}$ & $x$ & $x$ & \\
\hline & Total pharmaceutical spending & $\mathrm{X}$ & $x$ & $X$ & $x$ & $x$ & $X$ & $x$ & $X$ \\
\hline \multirow{4}{*}{$\begin{array}{l}\text { Financing } \\
\text { schemes }\end{array}$} & Government health schemes & & & & & & & & $X$ \\
\hline & Compulsory contributory health insurance schemes & & & & & & & & $X$ \\
\hline & Voluntary health insurance schemes & & & & & & & & $X$ \\
\hline & Out-of-pocket expenditure on health & & & & & & & & $X$ \\
\hline \multirow{2}{*}{ Providers } & Hospital health spending & & & & & & & & $\mathrm{x}$ \\
\hline & Ambulatory health spending & & & & & & & & $X$ \\
\hline \multirow{3}{*}{$\begin{array}{l}\text { Revenue of } \\
\text { schemes }\end{array}$} & Externally funded expenditure on health & & & & & & & & $x$ \\
\hline & Publicly funded expenditure on health & & & & & & & & $X$ \\
\hline & Privately funded expenditure on health & & & & & & & & $X$ \\
\hline Factors & Expenditure on human resources & & & & & & & & $x$ \\
\hline \multirow{3}{*}{ Beneficiaries } & Expenditure on health on non-communicable diseases & $x$ & $x$ & $x$ & $x$ & $x$ & $x$ & $x$ & $X$ \\
\hline & Expenditure on health on injuries & $x$ & $x$ & $X$ & $X$ & $x$ & $x$ & $x$ & $x$ \\
\hline & Expenditure on health age 65 and over & $x$ & $x$ & & & $x$ & $x$ & & $x$ \\
\hline \multirow{3}{*}{$\begin{array}{l}\text { Capital } \\
\text { formation }\end{array}$} & Total public spending on capital formation & $X$ & $x$ & & & & & & $X$ \\
\hline & Total private spending on capital formation & $x$ & & & & & & & $x$ \\
\hline & Spending on capital formation by hospitals & $x$ & & & & & & & $x$ \\
\hline
\end{tabular}

changes in functional financing within the system and to facilitate the possibility of forecasting and the use of simulation models.

Many countries have now developed time series of health accounts. Therefore, any HA report should present total expenditures and selected aggregates over time where these are available. To complete the tables, one can also include other useful reference data for computing selected indicators. The additional data usually reported include population size, GDP and a price index (preferably a medical/ [health] price index) over time.

When viewing a time series of health expenditures, it is commonly remarked that these have grown continuously through time. To properly analyse the time series data, it is important to determine first whether the increase was due to changes in the price, the content of the service or the quantity of the services provided. The effect of price increases can be removed through "deflating" health expenditure by converting to values in real terms or in constant prices, also referred to as "volumes" (see Chapter 13 for more detail). Then, to better appreciate the health expenditure trends over time, per capita real health expenditures, health expenditures as percentage of GDP, and average annual real growth rates may also be computed. Health expenditure values may be reported in national currency units and in PPP values. 


\section{Box 15.1. An example of an indicator on levels of care}

National needs for information vary extensively both between countries and over time. Health accounts provide a flexible toolkit to support analysis, and can be enlarged with minimal additional information requirements. Also, the analysis can use a variety of axes to explore the expenditure process under scrutiny. One example is the model of health care that considers the complexity of the health system and the structure of health needs in the population.

For example, levels of care can be separated into general and specialised types of services, which are introduced in the functional and provider classification of SHA 2011. In the following table, an example is presented in which the functions that deal with general and specialised care at the third-digit breakdown are included. Similarly, the provider classification can also be separated into general and specialised care providers. Functions and providers components without any special relevance to either area have been omitted from the table. The table then shows the amount of general care services consumed from providers of general care, and similarly the share of specialised services from providers of specialised care. Finally, the financing agents that pay for the services consumed are included in the example to identify the path for funding those matching profiles.

\section{Expenditure on health care by financing schemes and a selection of providers of care and functions}

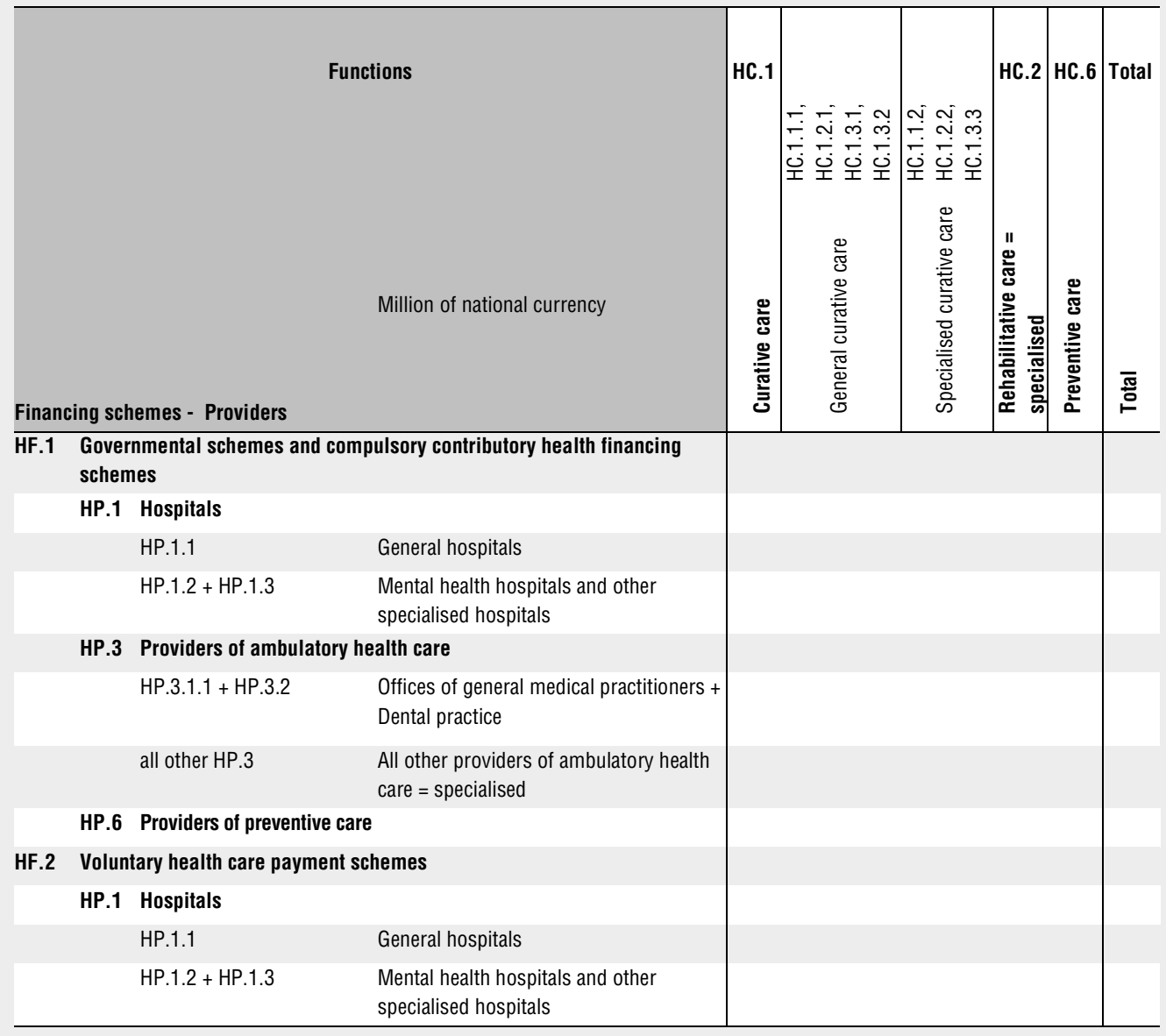




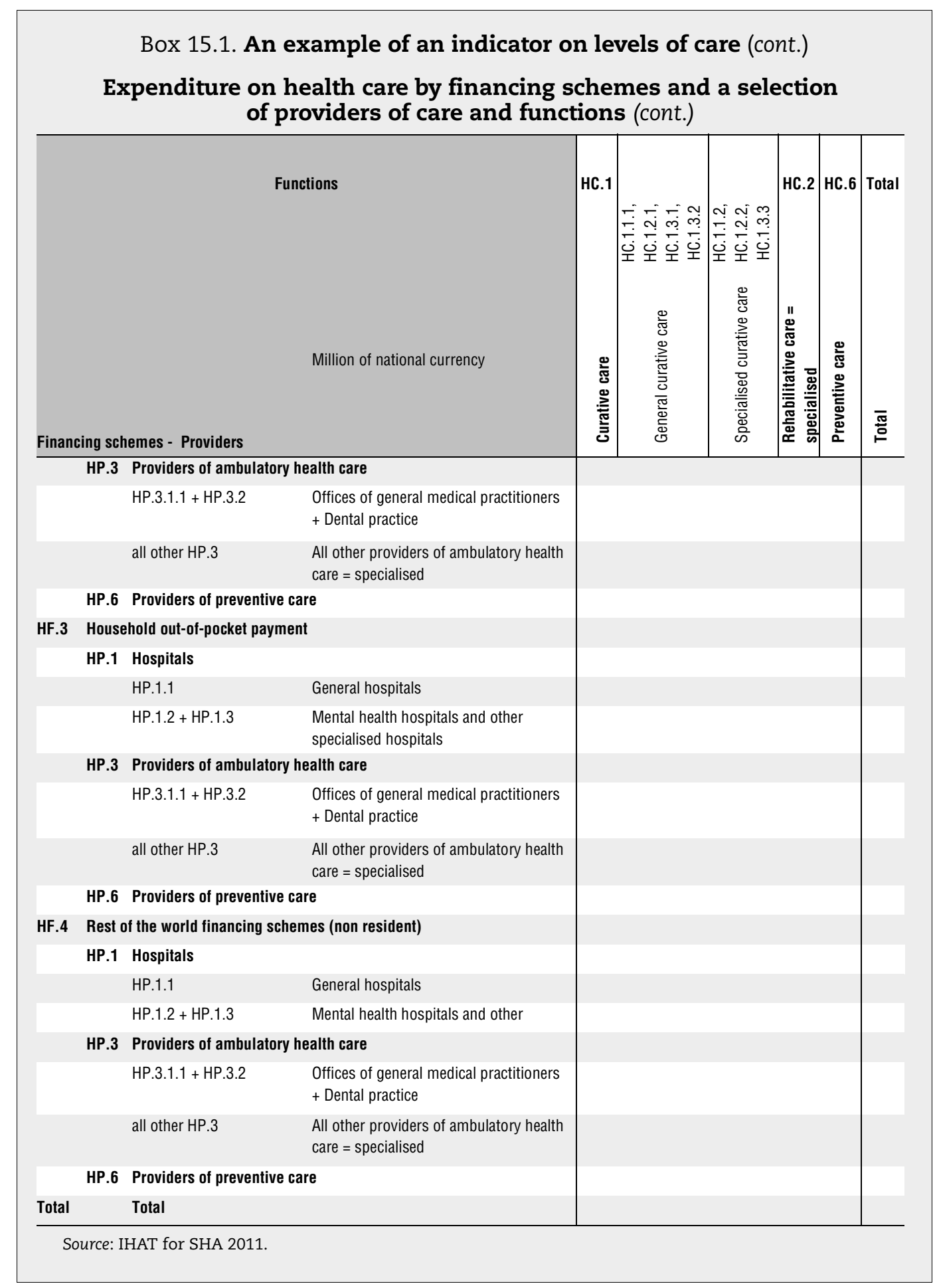

If a series of HA reports already exist, the current report should highlight any new patterns observed from the updated HA results. 


\section{Using HA with other health system information}

In addition to GDP, population and prices data, health accounts may also be reported together with other health system information to explore particular policy questions. For example, total expenditure on specific types of providers can be linked to measures of the service throughput of those providers in order to estimate average expenditure per unit of service delivered. More specifically, if a country's health accounts can separate hospital spending into government and non-government acute hospitals and if the total admissions into each type of hospital are known, then the average expenditure per admission for each type of hospital can be computed. Such comparisons may provide a useful first look at efficiency, although obviously further analysis is needed to explain any differences adequately.

These kinds of analyses or studies can be extensive in nature, and it is suggested that full accounts of these studies be reported in separate research or policy papers. Papers that have a specific policy focus can be more effective in communicating and informing concerned stakeholders of the facts about an existing situation and about what possible actions may be needed. The health accounts report can then present highlights or relevant findings extracted from these research or policy papers.

\section{Country background}

The health accounts report requires relevant background information to be sure that the results can be interpreted in their proper context. It is suggested that a summary description of the health care system be included. It should discuss the main financing flows, the actors involved, some contextual elements (e.g. the role of NGOs, of the private sector, of the external sector) and major policy issues (e.g. recent reforms, reforms under discussion, reforms required).

As indicated previously, it would be useful to have price index data in the HA report. Other data that may be valuable for interpreting HA results include statistics on providers and on health care utilisation and services provision, such as hospital bed-days, medical consultation visits, surgeries, immunisations and other key services, the volume of medicines and other health goods, and health outcomes data.

If a series of HA reports already exist, the current report should highlight new trends in health status, health facilities, health financing arrangements and health policies.

\section{Metadata and data sources}

The collection of the basic input data and the construction of the health accounts tables is a time-consuming effort. However, the effort will be much less worthwhile if the metadata behind the data are not properly documented. Solid, comprehensive metadata facilitates an appropriate interpretation and use of the HA results. For example, trends in health expenditures can be analysed better when there is knowledge about, say, changes in the accounting system. At a minimum, background information should include the sources of data, how data were validated (especially in the case of multiple data sources), the reasoning behind the selection of the data used in the estimation, the procedures applied to make the data usable, and more. 


\section{Quality checks}

A final set of checks on the quality of the HA data should be performed before publication in any report. These consist of checking for 1) the consistency of totals across tables, 2) consistency in the value of similar expense items across tables, and 3) the plausibility of percentage shares, per capita values, and growth rates. Checks on the quality of HA estimates are to be described further with some examples.

In the tri-axial approach, it is expected that the same total expenditures observed for consumption of health care should hold in the other axes of provision and financing. Basic quality checks include ensuring that the totals reported agree with the sums of the constituent parts. Identical items with identical classifications that appear in different tables should have the same value. Another set of quality checks should look into the plausibility of the various indicators in relation to the totals, in relation to the population (per capita data), in relation to GDP and in relation to historical values (percentage change from year to year, growth rates). Although the percentage shares and growth rates considered reasonable vary across countries, the relative changes should be within predetermined ranges of acceptability. For example, if private insurance is replaced by a government mandatory insurance scheme, then the relative change from one year to another in these two items would be significant, but in conformity with a real change.

\section{National, regional and international databases}

National, regional and international databases that report HA data have different purposes, scopes, and types of information and levels of detail available. All databases would contain time series, but different ranges or types of HA information. National databases primarily address data needs for country-level analysis, while regional and international databases provide data for examining cross-country issues and concerns.

National databases, being the repository of the country's HA estimates, tend to contain the most detailed information and estimates of specific health expenditure aggregates or components that may be memorandum items to the standard classifications, but which are of special interest to the country's policy makers. It is the responsibility of the national health accountants to include basic information that would help users to interpret the HA estimates properly as part of the databases; and these basic information should include definitions, data sources, computational procedures and other relevant information about the raw data used in the HA estimation.

Regional and international databases are constructed from information collected regularly from countries, using a standard table or questionnaire. The types of the information collected and the levels of detail are well-defined in the data collection instrument. The data sources and other relevant information used to arrive at the estimates being reported by countries in the standard questionnaire should be entered as explanatory notes. Steps have been taken to harmonise HA data collection efforts (for databases) of the different international agencies through the use of a jointly developed standard questionnaire.

The HA data of countries that is collected and reported in different regional and international databases are expected to be comparable, since countries presumably are using the same SHA methodology to generate their results and the data are collected for regional/international databases using a similar data collection instrument. Even so, differences between regional vs. international and national vs. international databases have been noted particularly for indicators. One important reason for differences has 
generally been the use of different sources for reference information. In the country database, national official data for GDP and population, for example, would be used, while some international databases use compilations of GDP and population by, say, the United Nations or the International Monetary Fund. Such differences can be put in a proper context so long as there is systematic documentation of the data sources and other relevant information in the databases.

For comparative purposes, however, it would be beneficial to ensure harmonised data reporting nationally and internationally for a given country. Reporting strategies and collaborative efforts between involved agencies are required to achieve that aim. Notably, one principle would be:

- To standardise categories and their expected content so that the values under one label would refer only to one single boundary and type of expenditure;

- To state clearly the reported coverage in time and in geographical area;

- To state clearly the reference values used and their source, time and coverage, e.g. gross domestic product (GDP), general government expenditure (GGE), population and exchange rates, etc.

\section{The selection of tables presented in this chapter}

In the section below, examples of the tables (at the second-digit level) mentioned above are presented. The presentation of this particular set of tables does not mean that any of them is mandatory or that the level of detail shown and the number of categories mentioned is recommended for country adoption.

\section{Notes}

1. It is important to understand that health accounts information will become routine information, and thus produced at a lower cost, if policy makers find the results useful and request the information regularly.

2. Expenditures targeted at some of the Millennium Development Goals can be monitored through this table.

3. See, for example, the European Community Health Indicators Monitoring (ECHIM), or the Health and Long-term care indicators under the EU Open Method Co-ordination Framework.

4. MERCOSUR: Mercado Comun del Sur (Trade agreement of the Southern-cone countries).

5. Although total health expenditure is no longer proposed in SHA 2011, the indicator current health expenditure plus capital spending is included here for continuity reasons with respect to SHA 1.0. 
Table 15.2. Expenditure on health care by financing schemes and functions of care

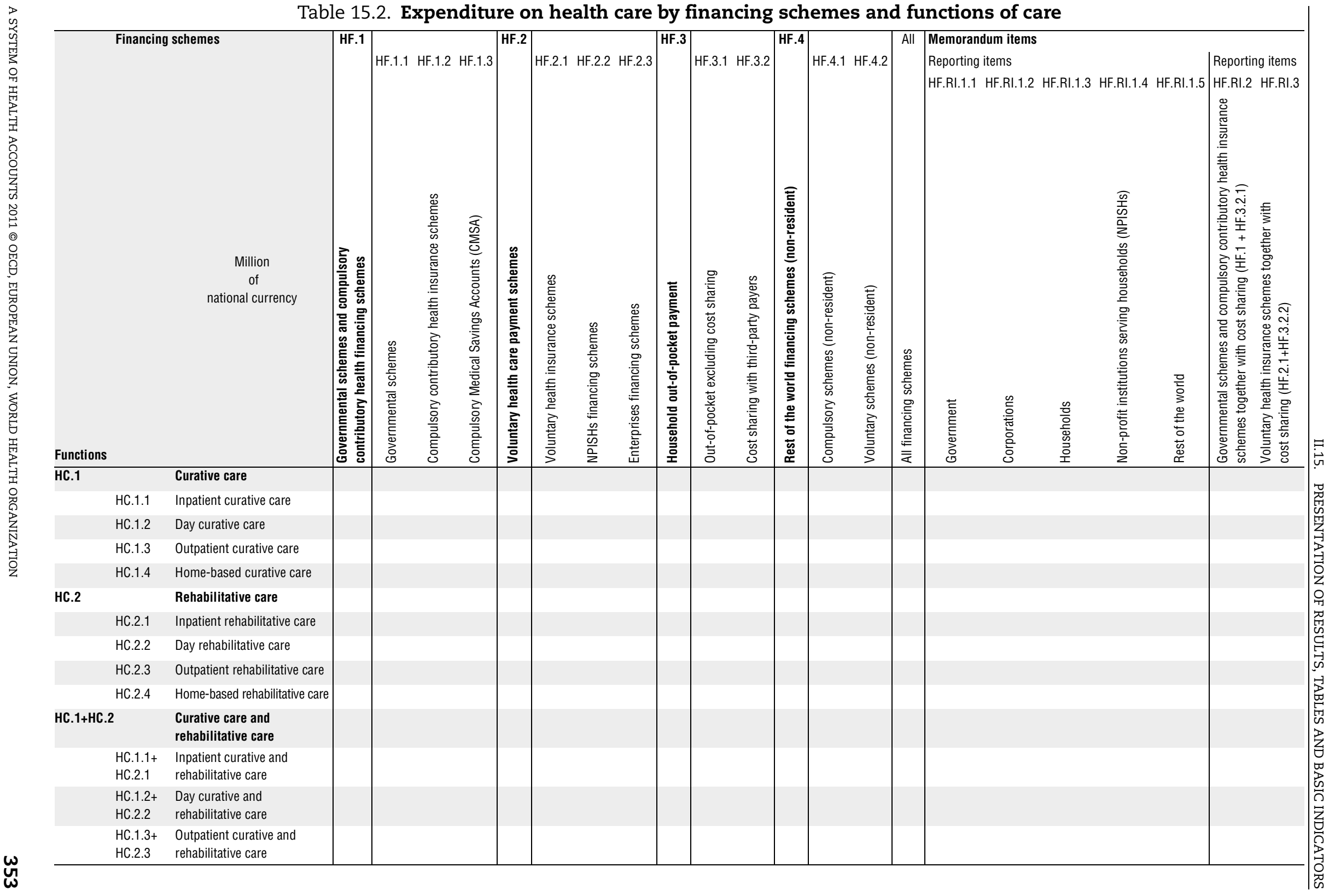


Table 15.2. Expenditure on health care by financing schemes and functions of care (cont.)

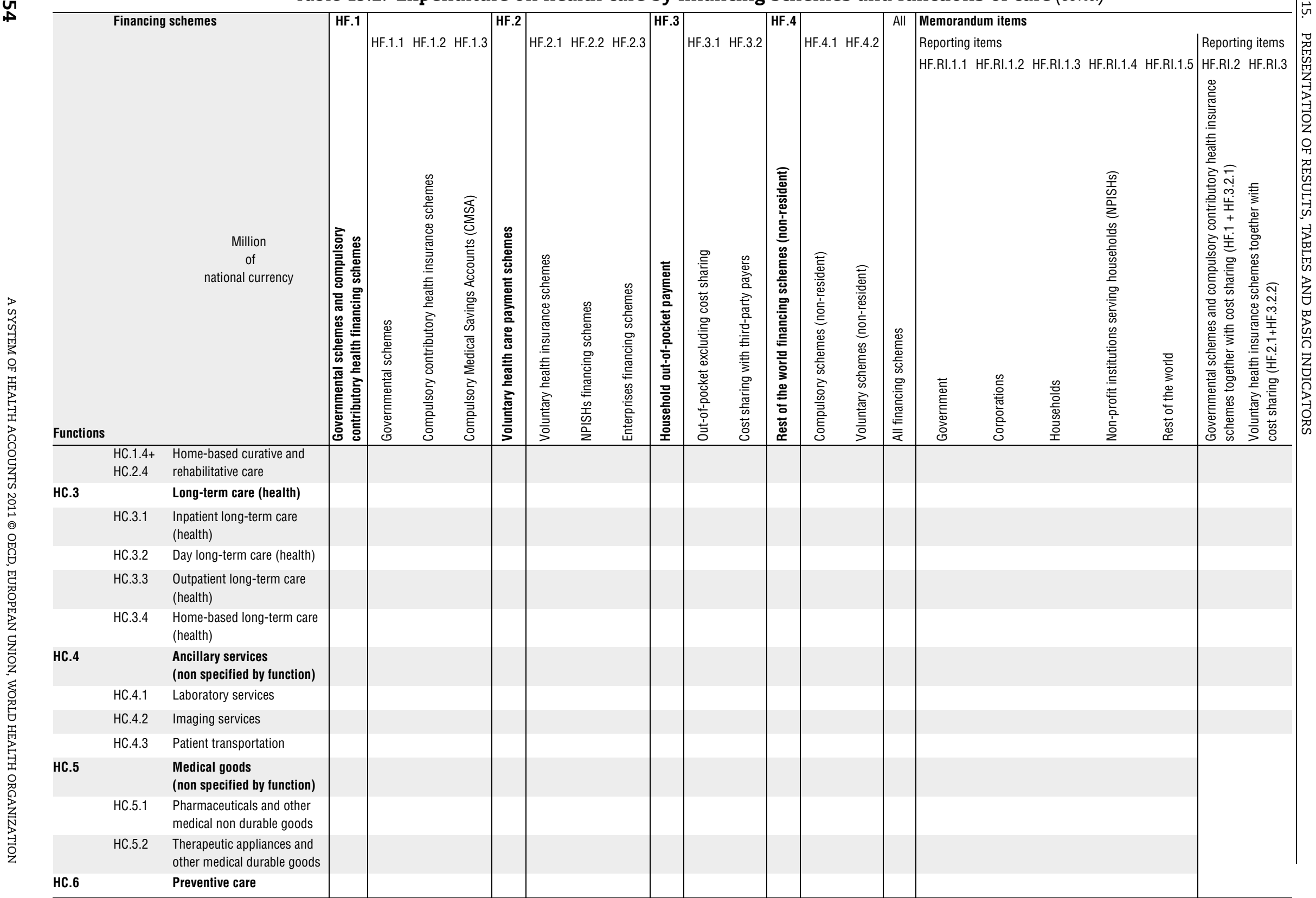


Table 15.2. Expenditure on health care by financing schemes and functions of care (cont.)

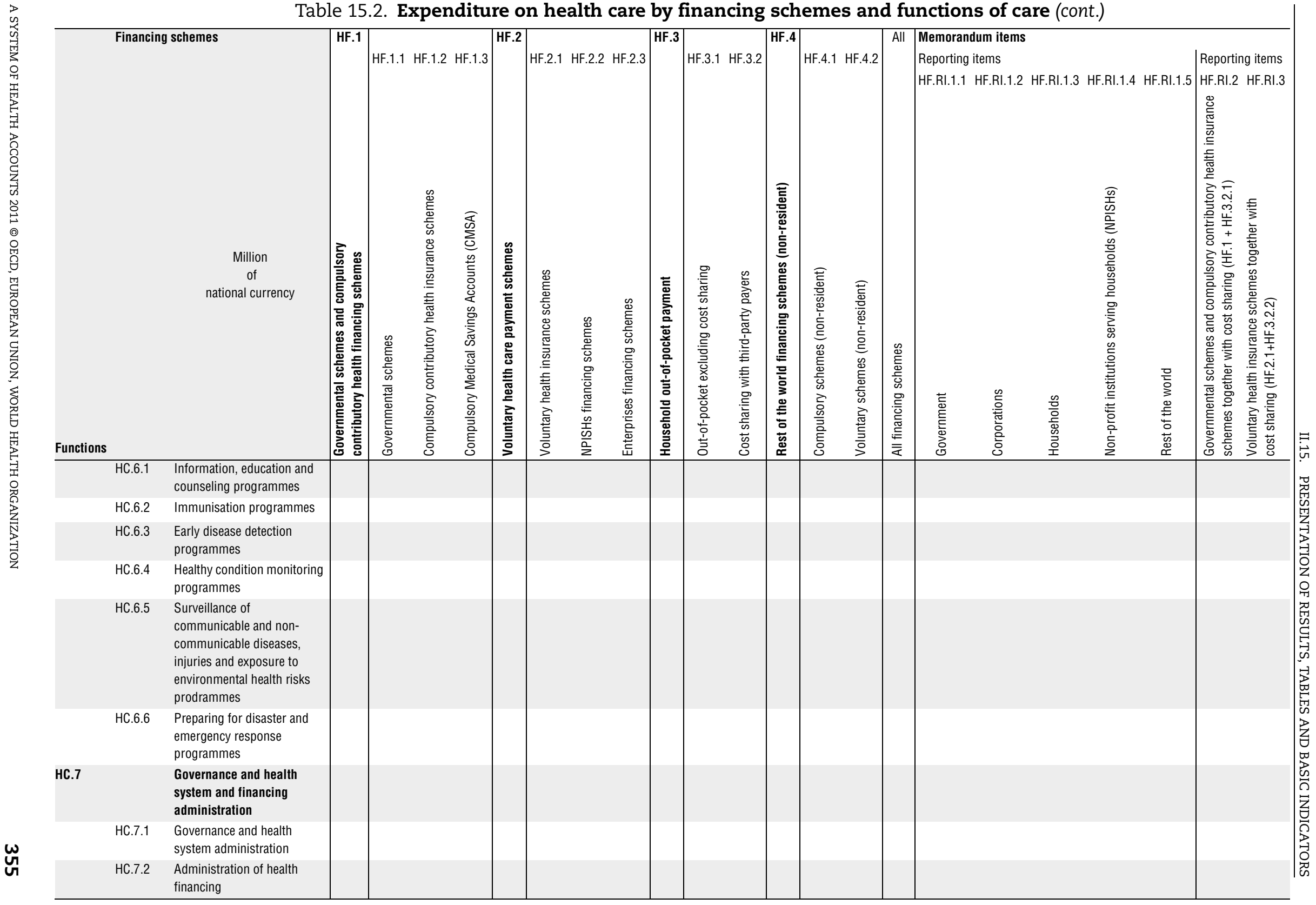


$\stackrel{\omega}{\circ}$

Table 15.2. Expenditure on health care by financing schemes and functions of care (cont.)

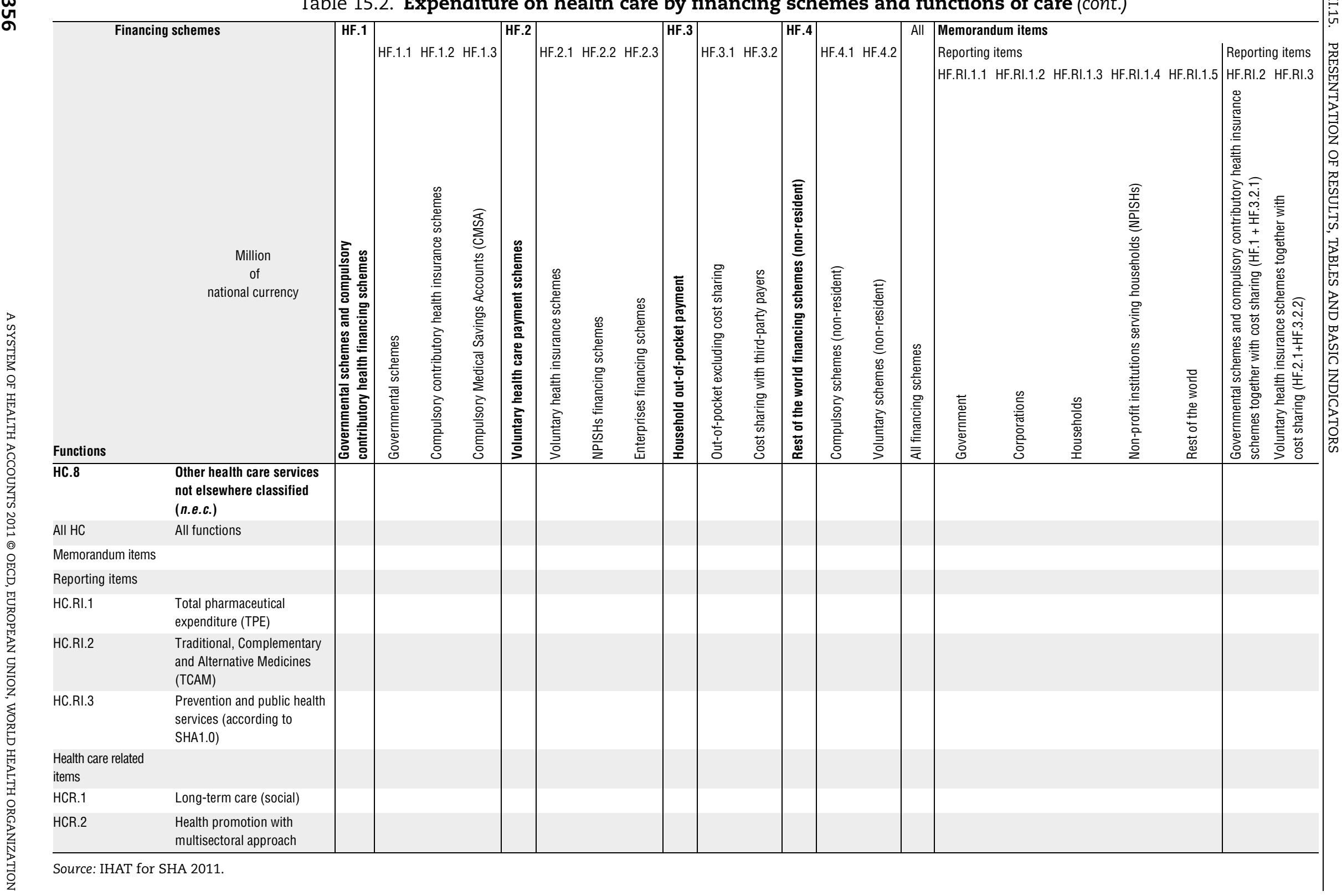


Table 15.3. Expenditure on health care by health care providers and functions of care

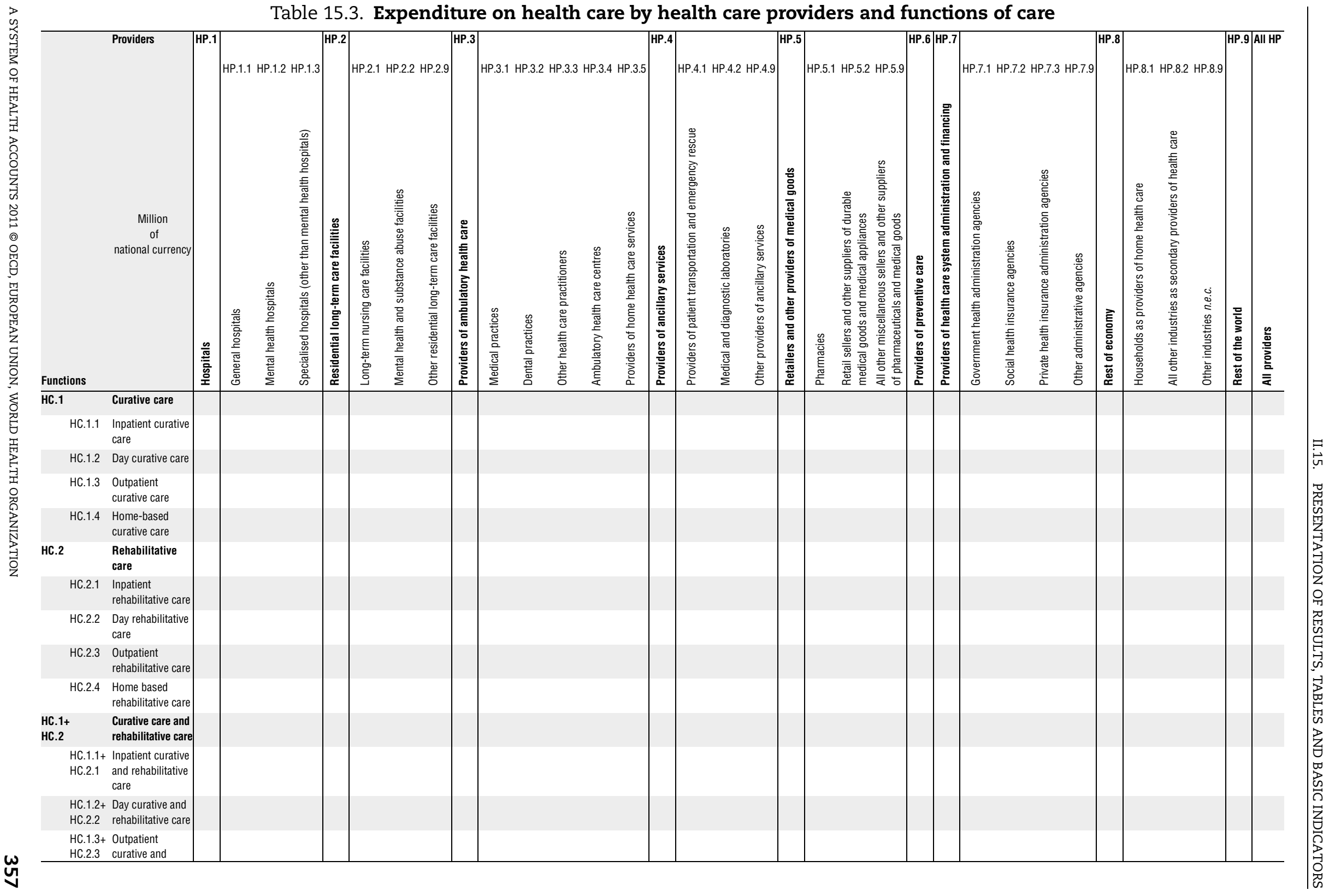


w

Table 15.3. Expenditure on health care by health care providers and functions of care (cont.)

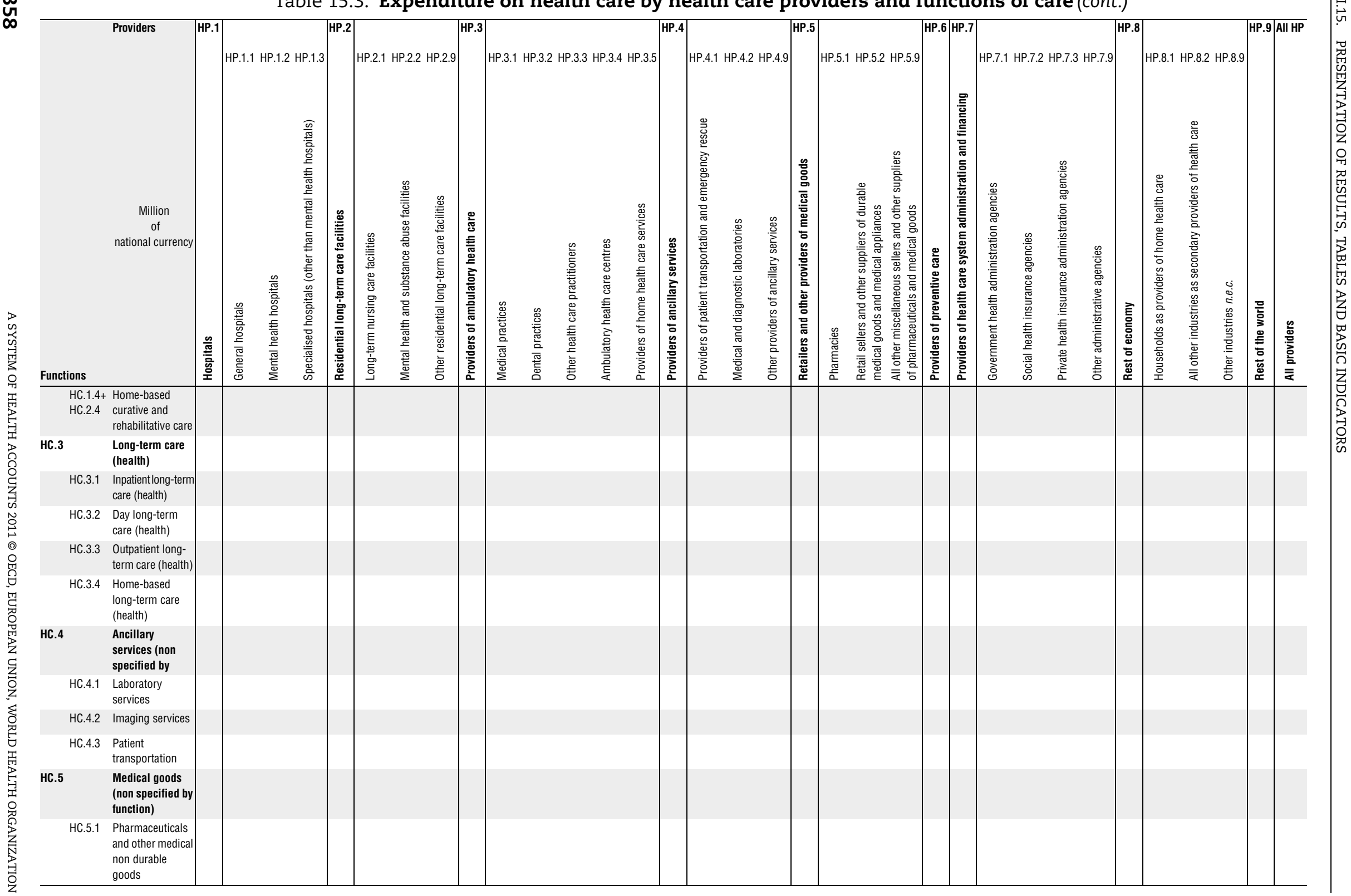


Table 15.3. Expenditure on health care by health care providers and functions of care (cont.)

\begin{tabular}{|c|c|c|c|c|c|c|c|c|c|c|c|c|c|c|c|c|c|c|c|c|c|c|c|c|c|c|c|c|c|c|c|c|c|c|}
\hline Functions & \begin{tabular}{c|} 
Providers \\
\\
Million \\
of \\
national currency
\end{tabular} & 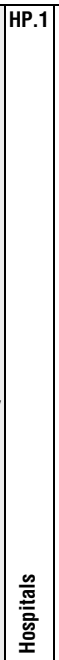 & 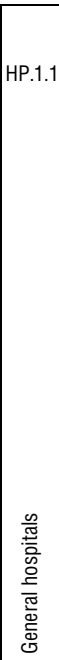 & 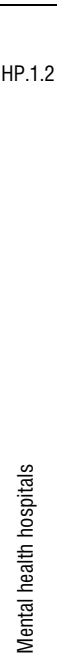 & 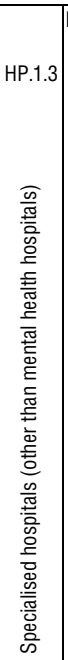 & 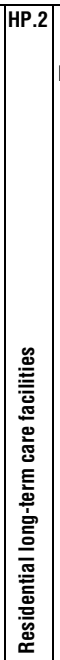 & 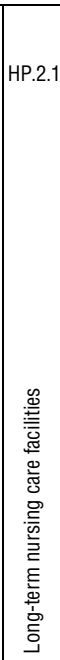 & 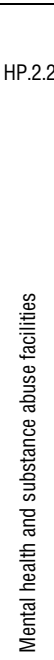 & 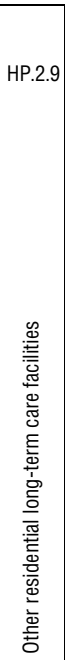 & 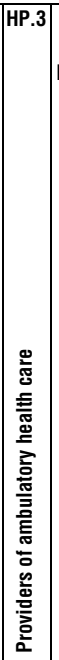 & 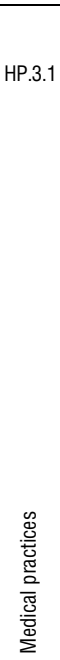 & 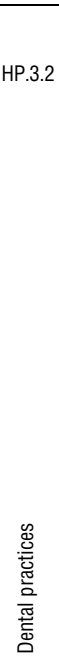 & 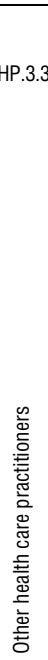 & 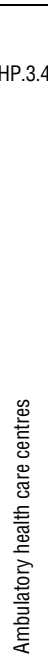 & 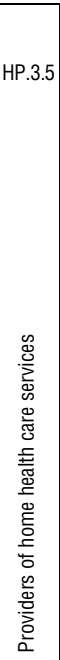 & 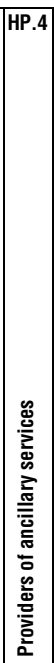 & 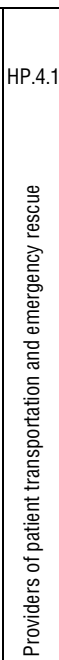 & 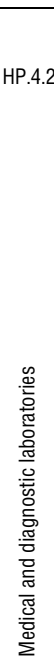 & 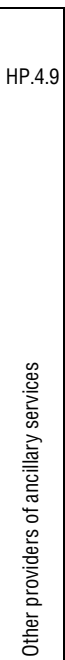 & 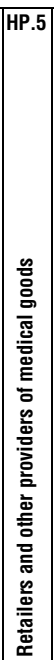 & HP.5.1 & 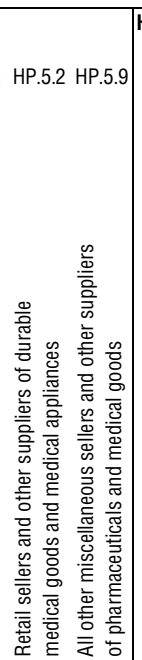 & 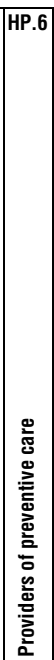 & 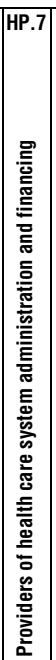 & 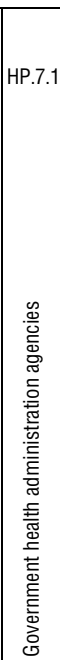 & 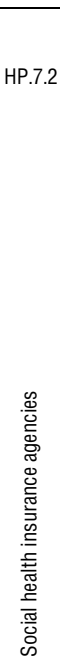 & 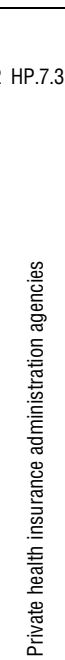 & 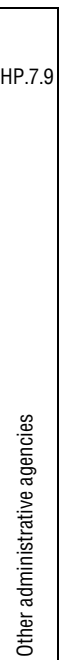 & 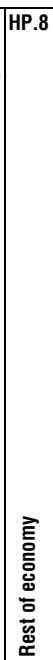 & 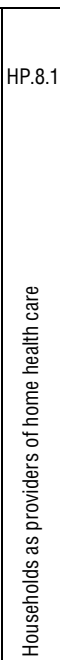 & 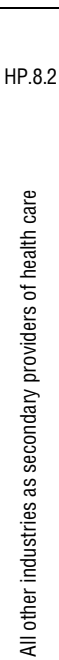 & 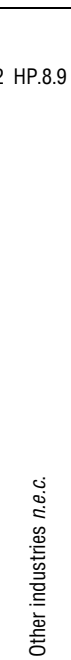 & 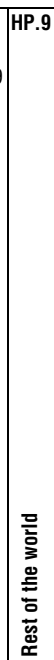 & 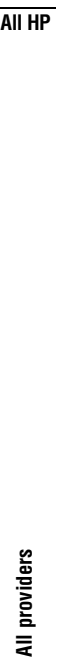 \\
\hline$\frac{\text { functions }}{H C .5 .2}$ & $\begin{array}{l}\text { Therapeutic } \\
\text { appliances and } \\
\text { other medical } \\
\text { durable goods }\end{array}$ & & & & & & & & & & & & & & & & & & & & & & & & & & & & & & & & & \\
\hline \multirow{2}{*}{$\begin{array}{l}\text { HC.6 } \\
\quad \text { HC.6.1 }\end{array}$} & Preventive care & & & & & & & & & & & & & & & & & & & & & & & & & & & & & & & & & \\
\hline & $\begin{array}{l}\text { Information, } \\
\text { education and } \\
\text { counseling } \\
\text { programmes }\end{array}$ & & & & & & & & & & & & & & & & & & & & & & & & & & & & & & & & & \\
\hline HC.6.2 & $\begin{array}{l}\text { Immunisation } \\
\text { programmes }\end{array}$ & & & & & & & & & & & & & & & & & & & & & & & & & & & & & & & & & \\
\hline HC.6.3 & $\begin{array}{l}\text { Early disease } \\
\text { detection } \\
\text { programmes }\end{array}$ & & & & & & & & & & & & & & & & & & & & & & & & & & & & & & & & & \\
\hline HC.6.4 & $\begin{array}{l}\text { Healthy condition } \\
\text { monitoring } \\
\text { programmes }\end{array}$ & & & & & & & & & & & & & & & & & & & & & & & & & & & & & & & & & \\
\hline HC.6.5 & $\begin{array}{l}\text { Surveillance of } \\
\text { communicable } \\
\text { and non- } \\
\text { communicable } \\
\text { diseases, injuries } \\
\text { and exposure to } \\
\text { environmental } \\
\text { health risks } \\
\text { prodrammes }\end{array}$ & & & & & & & & & & & & & & & & & & & & & & & & & & & & & & & & & \\
\hline HC.6.6 & $\begin{array}{l}\text { Preparing for } \\
\text { disaster and } \\
\text { emergency } \\
\text { response } \\
\text { programmes }\end{array}$ & & & & & & & & & & & & & & & & & & & & & & & & & & & & & & & & & \\
\hline
\end{tabular}




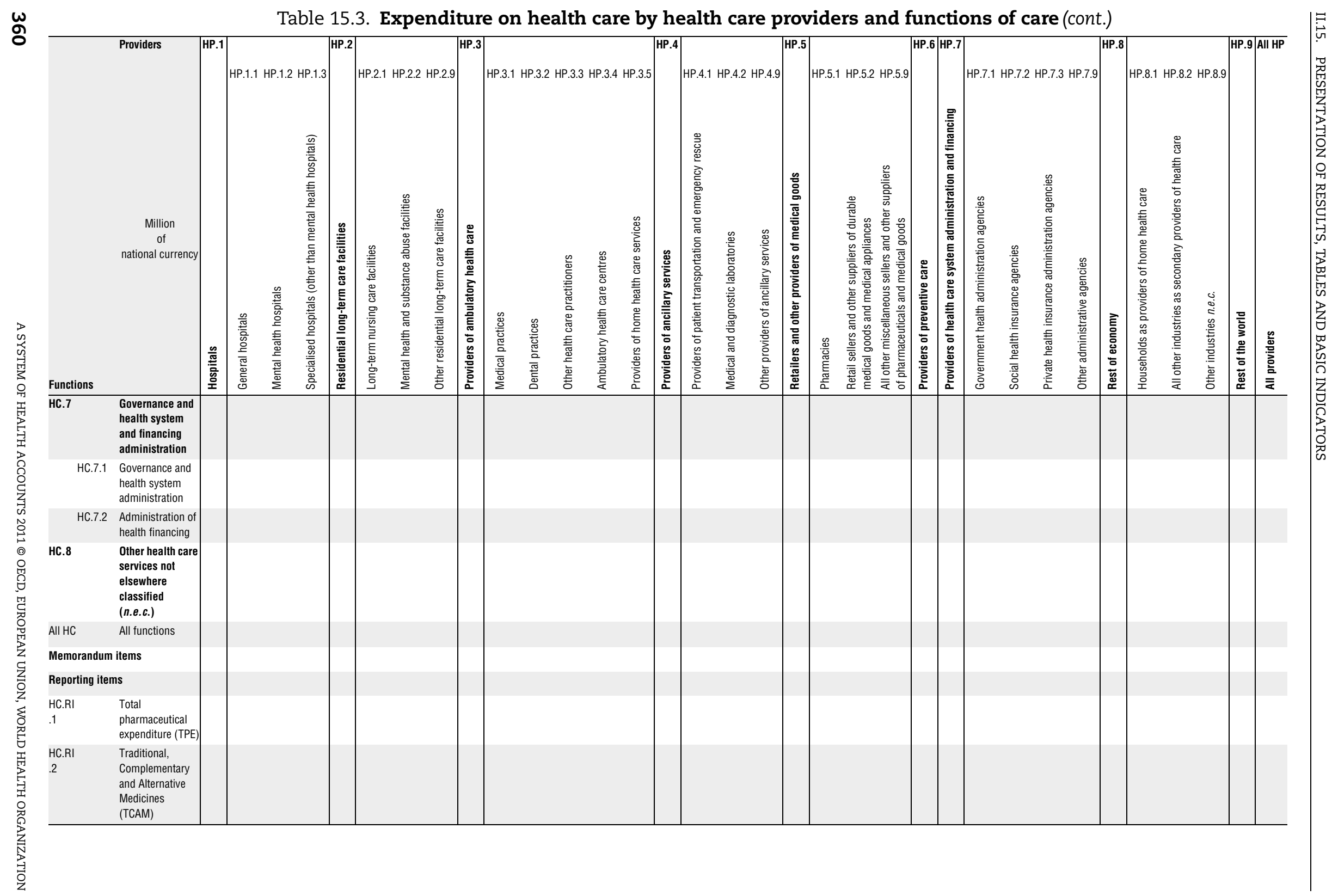




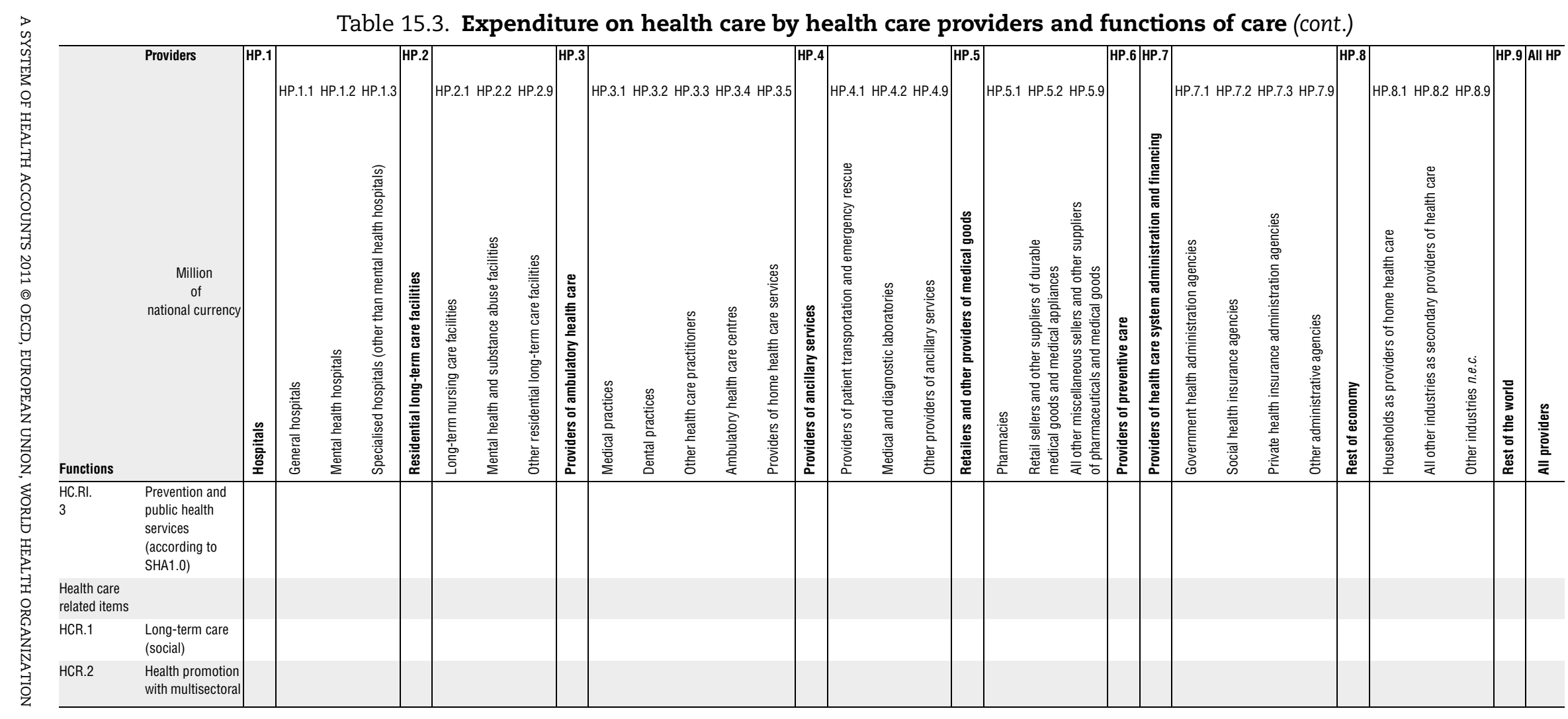


Table 15.4. Expenditure on health care by financing schemes and health care providers (cont.)

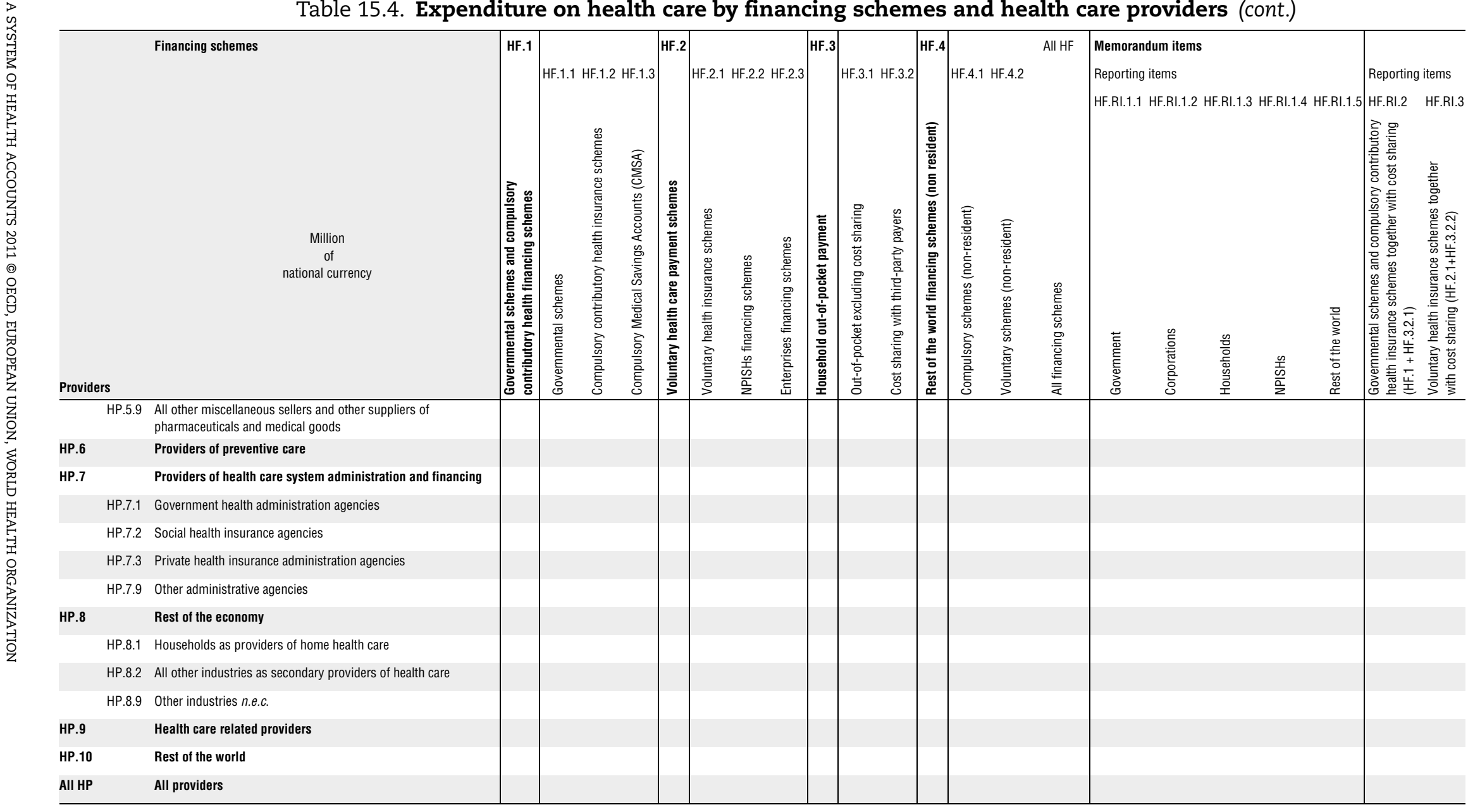

Source: IHAT for SHA 2011. 
$\stackrel{\omega}{\Phi}$

Table 15.5. Expenditure on health care by revenues of financing schemes and financing schemes

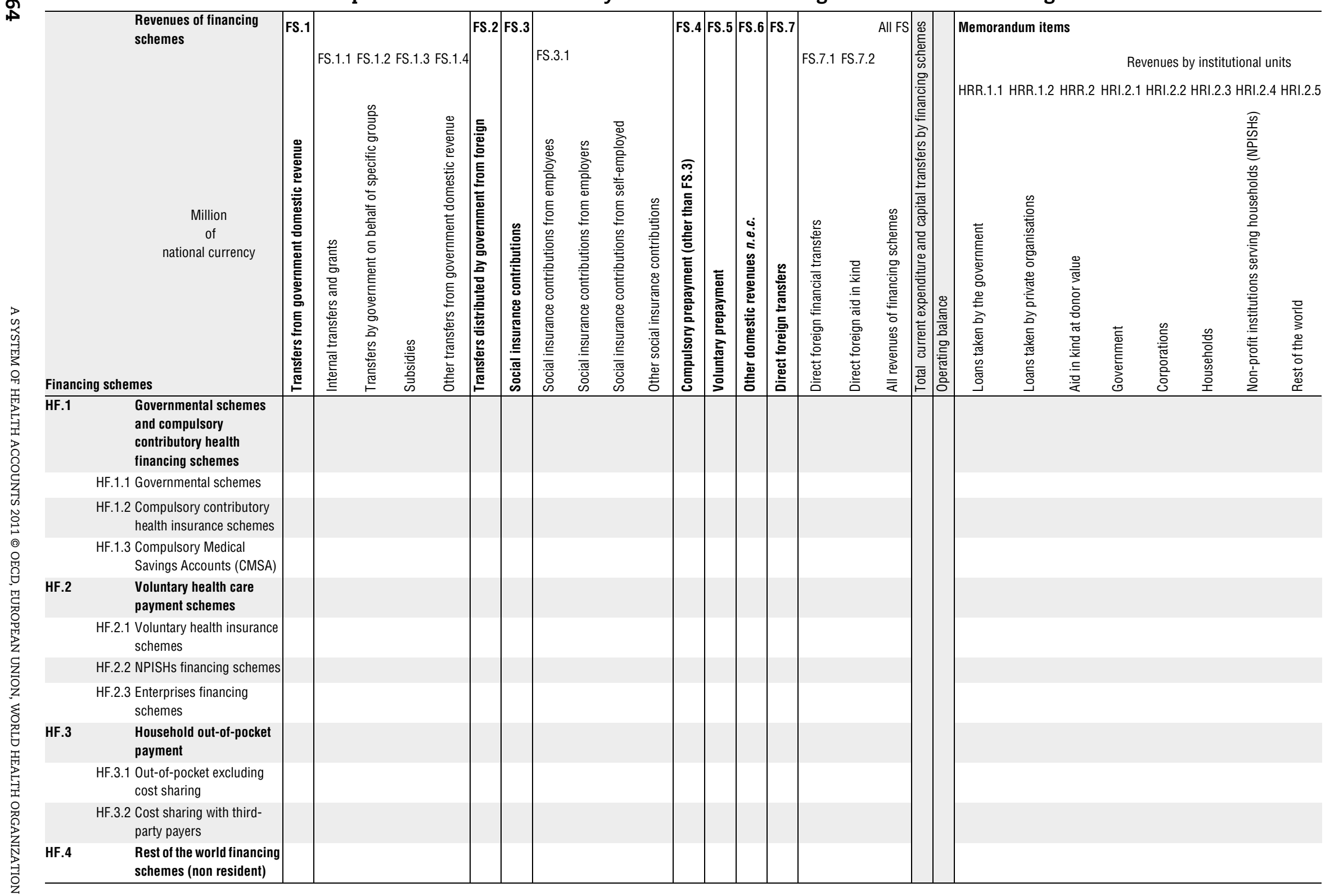




\section{Table 15.5. Expenditure on health care by revenues of financing schemes and financing schemes (cont.)}

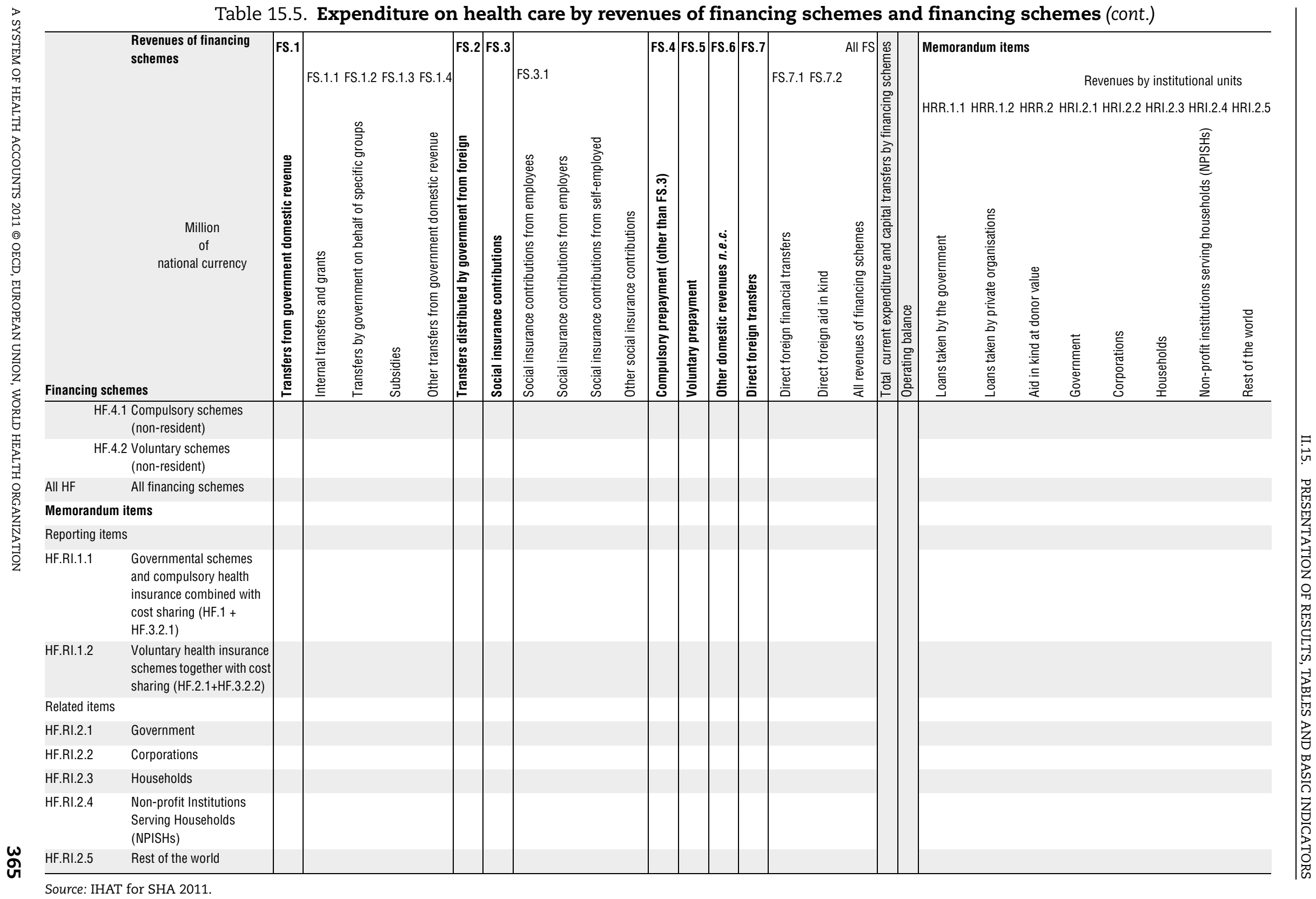


Table 15.6. Expenditure on health care by financing agents and financing schemes (cont.)

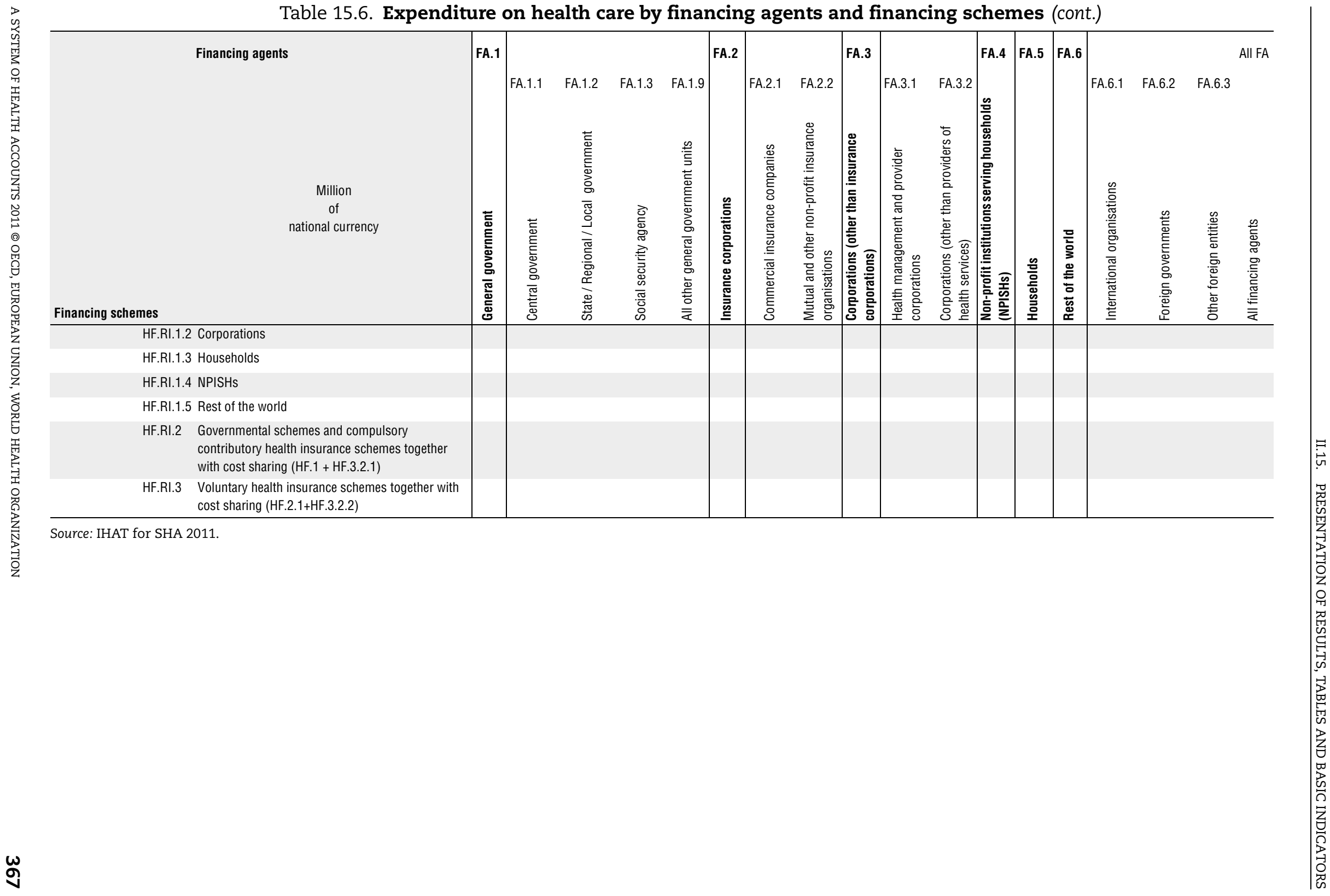


Table 15.7. Expenditure on health care by factors of provision and health care providers

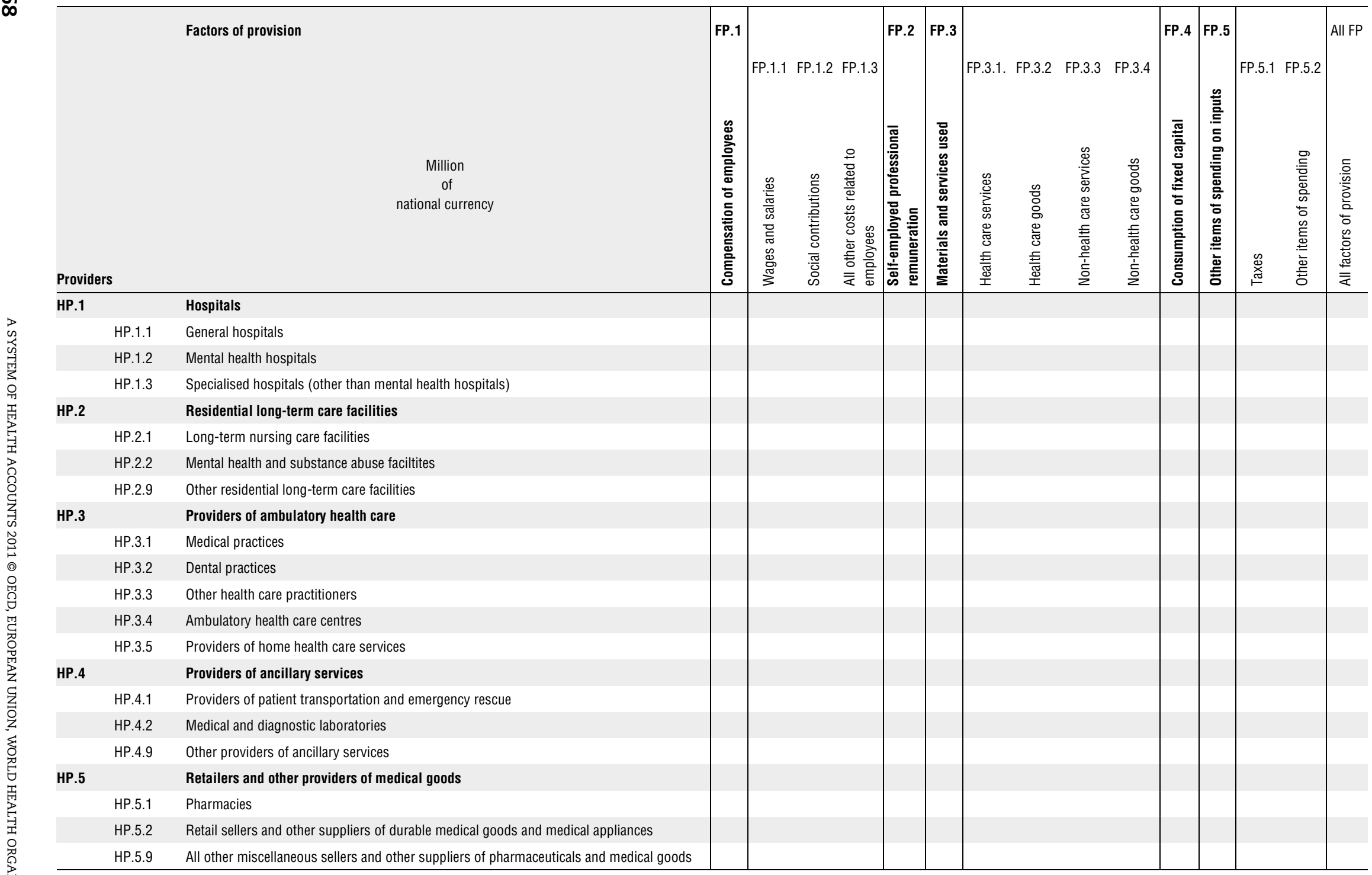


Table 15.7. Expenditure on health care by factors of provision and health care providers (cont.)

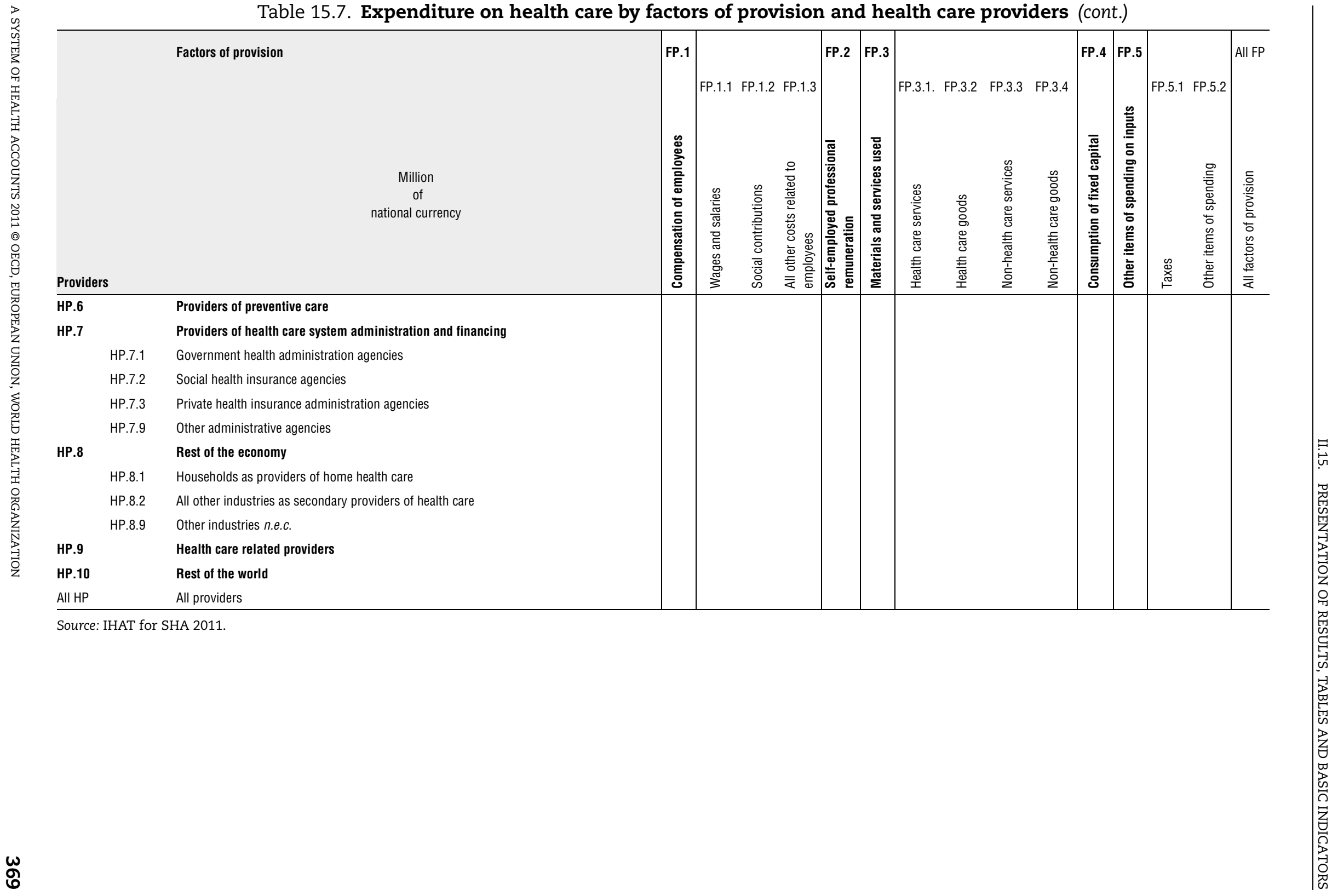




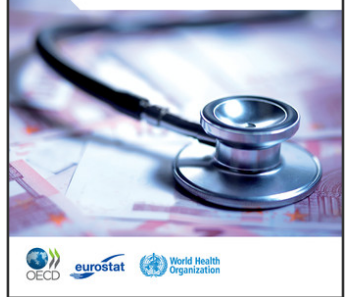

\section{From:}

A System of Health Accounts

2011 Edition

Access the complete publication at:

https://doi.org/10.1787/9789264116016-en

\section{Please cite this chapter as:}

OECD/World Health Organization/Eurostat (2011), "Presentation of Results, Tables and Basic Indicators", in A System of Health Accounts: 2011 Edition, OECD Publishing, Paris.

DOI: https://doi.org/10.1787/9789264116016-17-en

This work is published under the responsibility of the Secretary-General of the OECD. The opinions expressed and arguments employed herein do not necessarily reflect the official views of OECD member countries.

This document and any map included herein are without prejudice to the status of or sovereignty over any territory, to the delimitation of international frontiers and boundaries and to the name of any territory, city or area.

You can copy, download or print OECD content for your own use, and you can include excerpts from OECD publications, databases and multimedia products in your own documents, presentations, blogs, websites and teaching materials, provided that suitable acknowledgment of OECD as source and copyright owner is given. All requests for public or commercial use and translation rights should be submitted to rights@oecd.org. Requests for permission to photocopy portions of this material for public or commercial use shall be addressed directly to the Copyright Clearance Center (CCC) at info@copyright.com or the Centre français d'exploitation du droit de copie (CFC) at contact@cfcopies.com. 